\title{
Etiology and Perinatal Outcome of Nonimmune Hydrops Fetalis in Southern China
}

\author{
Sheng He, PhD ${ }^{1, *}$ Linlin Wang, MD ${ }^{1, *}$ Pingshan Pan, MD ${ }^{1} \quad$ Hongwei Wei, MD ${ }^{1}$ Dahua Meng, BD ${ }^{1}$ \\ Juan Du, BD ${ }^{1}$ Xiaoxian Tian, BD ${ }^{1}$ Chenguang Zheng, $\mathrm{PhD}^{1}$ Xiaoxia Qiu, $\mathrm{PhD}^{1}$ Guoyang Luo, MD, $\mathrm{PhD}^{2}$
}

1 Prenatal Diagnosis Center, Guangxi Zhuang Autonomous Region Women and Children Care Hospital, Nanning, People's Republic of China

2 Department of Obstetrics and Gynecology, University of Connecticut, Farmington, Connecticut
Address for correspondence Xiaoxia Qiu, PhD, Guangxi Zhuang Autonomous Region Women and Children Care Hospital. No.59, Xiangzhu Road, Nanning City, 530033, Guangxi, China (e-mail: qiuxiaoxia1958@163.com).

Am J Perinatol Rep 2017;7:e111-e115.

\begin{abstract}
Keywords

- nonimmune hydrops fetalis

- NIHF

- causes

- Hb Bart's disease

- thalassemia

Objective This study aims to analyze the etiology and perinatal outcome of nonimmune hydrops fetalis (NIHF) in Southern China.

Methods All cases with NIHF diagnosed antenatally from January 1, 2007 to December 31, 2014 were identified and analyzed.

Results Total 482 cases of NIHF were identified during the study period. The most common cause of NIHF was hemoglobin $(\mathrm{Hb})$ Bart's disease $(61.8 \%)$, followed by chromosomal abnormalities (13.5\%), idiopathic etiology (13.1\%), cardiac abnormalities (6.4\%), and others (5.2\%). After 20 weeks' gestation, a total of 408 cases of NIHF presented, including Hb Bart's disease (279 cases), cardiac abnormalities (27 cases), and infection (7 cases). NIHF caused by chromosomal abnormalities mainly presented between 15 and 19 weeks' gestation. Of the 482 cases, 459 cases elected termination of pregnancy. The remaining 23 cases elected to continue their pregnancy. Among them, $14(60.9 \%)$ resulted in intrauterine fetal death, 6 had neonatal death, 3 infants survived to 1 year of age. Of the three infants, one has cerebral palsy, and the remaining two are normal.

Conclusions Hb Bart's disease is the most common cause of NIHF in Southern China. An effective prenatal screening and counseling program for thalassemia in this region may be the most effective way to lower the incidence NIHF.
\end{abstract}

Hydrops fetalis is defined as diffuse excess fluid accumulation in two or more fetal body cavities that occur during gestations. This condition is frequently recognized by ultrasonography in pregnancy and affects $1: 1,500$ to $1: 3,750$ deliveries, with a perinatal mortality rate ranging from 55 to $98 \%{ }^{1-3}$ The etiologies of fetal hydrops can be classified as immune and nonimmune types. Nonimmune hydrops fetalis (NIHF) is now the most common type of fetal hydrops. It is estimated that approximately $90 \%$ of all cases of fetal hydrops

Sheng He and LinLin Wang are co-first authors. are of nonimmunological origin. ${ }^{4}$ The overall morbidity and mortality rates are linked to the underlying causes of hydrops. More than 80 different diseases have been found to be associated with fetal hydrops. ${ }^{5}$ Although many causes of fetal hydrops can be amenable by intrauterine treatment which leads to fetal salvage, the mortality of fetal hydrops remains high. The identification of the associated etiologies of NIHF is important for prenatal counseling and management of current and future pregnancies.

Although the etiologies of fetal hydrops have been reported in previous studies, they vary widely among received

March 4, 2017

accepted after revision

May 11, 2017
DOI https://doi.org/

10.1055/s-0037-1603890. ISSN 2157-6998.
Copyright $\odot 2017$ by Thieme Medical Publishers, Inc., 333 Seventh Avenue, New York, NY 10001, USA. Tel: +1(212) 584-4662.
License terms

(요 (1) $\Theta \circledast$ 
different populations at different regions. ${ }^{6-10}$ In this study, we investigated the etiologies and perinatal outcome of NIHF in Southern China.

\section{Materials and Methods}

This retrospective study was performed at the Guangxi Zhuang Autonomous Region Women and Children Care Hospital, one of the largest tertiary referral centers in Southern China. All cases with fetal hydrops diagnosed antenatally from January 1, 2007 to December 31, 2014 were identified, and the medical records were reviewed. Fetal hydrops was defined as an excessive fluid collection in more than two fetal body cavities, and all cases with isoimmunization were excluded. All cases had complete ultrasonographic examinations. If an obvious cause of hydrops other than chromosomal abnormalities was determined, such as congenital cystic adenomatoid malformation, or twin-twin transfusion syndrome (TTTS), the etiology was then investigated after delivery. If fetal abnormalities were detected, fetal chromosomal analysis (microarray since 2013) was offered. Middle cerebral artery Doppler ultrasound was performed to rule out fetal anemia. Maternal hemoglobin electrophoresis, Kleihauer-Betke test, maternal serology to exclude toxoplasmosis, rubella, cytomegalovirus, herpes simplex (collectively known as "TORCH") and parvovirus B19, and rapid plasma reagin to screen for syphilis were performed. If the screening for $\alpha$-thalassemia or infection was positive, fetal blood sampling was then performed to confirm the diagnosis. After throughout evaluation, the patient and her family were appropriately counseled about the pregnancy outcome. Maternal characteristics, serological results, sonographic findings, pregnancy outcomes, postmortem examinations for those elected for termination or stillbirth or neonatal death were recorded.

\section{Results}

During the study period, total 482 cases of NIHF were identified. Overall, 165 cases were from our hospital, and the remaining 317 cases were referred from other hospitals across the region. The median maternal age was 25 years (range: 21-42 years), and the mean gestational age at diagnosis of fetal hydrops was 24 weeks (range: 13-35 weeks). A total of 32 patients had a prior pregnancy affected with fetal hydrops: Hemoglobin ( $\mathrm{Hb}$ ) Bart's disease caused 30 pregnancies, and the remaining 2 pregnancies had unknown etiology.

The etiologies and pregnancy outcomes of all NIHF are summarized in - Table 1. The causes of NIHF were identified in 419 of $482(86.9 \%)$ cases. The most common cause was $\mathrm{Hb}$ Bart's disease (298 cases, $61.8 \%$ ), followed by chromosomal abnormalities ( 65 cases, 13.5\%), idiopathic etiology (63 cases, $13.1 \%$ ), cardiac abnormalities ( 31 cases, $6.4 \%$ ), and infection ( 7 cases, $1.5 \%$ ), other structural anomalies ( 7 cases, $1.5 \%$ ), TTTS ( 4 cases, $0.8 \%$ ), meconium peritonitis ( 4 cases, $0.8 \%$ ), chylous ( 3 cases, $0.6 \%$ ). The gestational age of all cases at diagnosis according to etiology are summarized in - Table 2.
The majority cases of NIHF (408 cases, $84.6 \%$ ) were diagnosed after 20 weeks' gestation.

Among the 298 cases with Hb Bart's disease, 294 cases (98.7\%) were caused by homozygous - $-{ }^{\text {SEA }}$ deletions ( $\left.{ }^{\mathrm{SEA}} /{ }_{-}{ }^{\mathrm{SEA}}\right)$. Three cases were caused by compound heterozygous $-{ }^{\mathrm{SEA}}$ and $-{ }^{\mathrm{THAI}}$ deletions $\left(--{ }^{\mathrm{SEA}} /-{ }^{\mathrm{THAI}}\right)$, and the remaining case was caused by a compound heterozygous ${ }^{\mathrm{SEA}}$ and $--^{210 \mathrm{~Kb}}$ deletions $\left(--{ }^{\mathrm{SEA}} /-{ }^{210 \mathrm{~Kb}}\right)$. All cases had typical sonographic findings such as cardiomegaly, marked dilatation of the umbilical vein (more than $10 \mathrm{~mm}$ ), placental edema, or oligohydramnios. The majority cases (279 cases, 93.6\%) of $\mathrm{Hb}$ Bart's hydrops fetalis were diagnosed after 20 weeks' gestation, with the median gestational age at 25 weeks (range: 13-34 weeks).

Chromosome abnormalities were identified in 65 cases (13.5\%) of NIHF. Turner's syndrome was the most common chromosome abnormality (33 cases, $51 \%$ ), followed by trisomy 21 (16 cases, 24.6\%), trisomy 18 (9 cases, 13.8\%), and trisomy 13 ( 5 cases, $7.7 \%$ ). Other chromosomal abnormalities included one case of 46,XY,der(18),t(7;18)(q22;q23) and a case of $46, X X,+\operatorname{der}(22) t(11 ; 22)(q 23 ; q 11)$ mat. The median maternal age in fetuses with aneuploidy was 33 years (range: 28-42 years). Advanced maternal age ( $>35$ years) was documented in 48 out of 65 cases. Most cases (52.3\%) were diagnosed with hydrops between 15 and 19 gestational weeks (-Table 2 ).

Cardiac abnormalities were the third most common causes of NIHF (31 cases, 6.4\%), including 14 cases of fetal arrhythmia, 10 cases of congenital heart block, and 7 cases of cardiac malformations. The cardiac malformations included one case of complete endocardial cushion defect, three cases of severe tricuspid regurgitation, two cases of rhabdomyoma of heart, and one case of a complex cardiac anomaly. A total of 25 (80.6\%) cases presented with hydrops after 25 weeks of gestation.

There were seven cases of infection-caused fetal hydrops, including two cases with parvovirus B19 and five cases with cytomegalovirus. All cases were confirmed by amniotic fluid or fetal blood test and postmortem examination. The median gestational age at presentation was 23 weeks.

There were 63 cases (13.1\%) of NIHF with an unknown etiology after prenatal, postnatal, and postmortem examinations. Of the 63 cases, 50 cases (79.3\%) were presented with fetal hydrops after 20 weeks of gestation.

Pregnancy outcomes are summarized in - Table 1. After extensive counseling, 459 cases (95.2\%) elected termination of pregnancy. The remaining 23 cases (4.8\%) elected to continue their pregnancy. Among them, 14 cases (60.9\%) resulted in intrauterine fetal death, the remaining 9 cases (39.1\%) survived to birth. Of these nine infants, six had neonatal death; three survived to 1 year of age. Of the three infants, one was diagnosed with cerebral palsy, and two were normal.

\section{Discussion}

Fetal hydrops occurs as a result of abnormal fluid homeostasis which leads to net efflux of water from fetal capillary 
Table 1 Etiologies and perinatal outcomes of nonimmune hydrops fetalis in Southern China

\begin{tabular}{|c|c|c|c|c|c|c|}
\hline Etiologies & Number & TOP & IUFD & ND & $\begin{array}{l}1 \mathrm{y} \text { without } \\
\text { complications }\end{array}$ & $\begin{array}{l}1 \mathrm{y} \text { with } \\
\text { complications }\end{array}$ \\
\hline Hb Bart's hydrops & $\begin{array}{l}298 \\
(61.8 \%)\end{array}$ & 298 & 0 & 0 & 0 & 0 \\
\hline $\begin{array}{l}\text { Abnormal } \\
\text { chromosomes }\end{array}$ & $\begin{array}{l}65 \\
(13.5 \%)\end{array}$ & 65 & 0 & 0 & 0 & 0 \\
\hline Turner syndrome & 33 & & & & & \\
\hline Trisomy 21 & 16 & & & & & \\
\hline Trisomy 18 & 9 & & & & & \\
\hline Trisomy 13 & 5 & & & & & \\
\hline Others & 2 & & & & & \\
\hline Cardiac $^{\mathrm{a}}$ & $31(6.4 \%)$ & 27 & 2 & 2 & 0 & 0 \\
\hline Fetal arrhythmia & 14 & 12 & 1 & 1 & 0 & 0 \\
\hline Cardiac malformations & 7 & 7 & 0 & 0 & 0 & 0 \\
\hline Congenital heart block & 10 & 8 & 1 & 1 & 0 & 0 \\
\hline Infections & $7(1.5 \%)$ & 3 & 4 & 0 & 0 & 0 \\
\hline Parvovirus B19 & 2 & 2 & 0 & 0 & 0 & 0 \\
\hline CMV & 5 & 1 & 4 & 0 & 0 & 0 \\
\hline TTTS & $4(0.8 \%)$ & 2 & 2 & 0 & 0 & 0 \\
\hline Thanatophoric dysplasia & $2(0.2 \%)$ & 2 & 0 & 0 & 0 & 0 \\
\hline Twin aortic perfusion & $1(0.2 \%)$ & 1 & 0 & 0 & 0 & 0 \\
\hline Chylous & $3(0.6 \%)$ & 0 & 1 & 1 & 1 & 0 \\
\hline CCAM & $3(0.6 \%)$ & 0 & 2 & 1 & 0 & 0 \\
\hline Meconium peritonitis & $4(0.8 \%)$ & 0 & 2 & 1 & 1 & 0 \\
\hline Diaphragmatic hernia & $1(0.2 \%)$ & 1 & 1 & 0 & 0 & 0 \\
\hline Idiopathic & $\begin{array}{l}63 \\
(13.1 \%)\end{array}$ & 60 & 1 & 1 & 0 & 1 \\
\hline Total & $\begin{array}{l}482 \\
(100 \%)\end{array}$ & 459 & 14 & 6 & 2 & 1 \\
\hline
\end{tabular}

Abbreviations: CCAM, congenital cystic adenomatoid malformation of the lung; CMV, cytomegalovirus; IUFD, intrauterine fetal death; ND, neonatal death; TOP, termination of pregnancy; TTTS, twin-to-twin transfusion syndrome.

plasma into interstitial tissues. More than 80 causes or associations of NIHF have been found. The etiology varies with the ethnic population and region studied. ${ }^{10,11}$ The most common cause of NIHF in our study was Hb Bart's disease (61.8\%), which is different from those in western countries where cardiac abnormalities, chromosome abnormalities, and infections were the most common causes of NIHF. ${ }^{7,12,13}$ Our results were consistent with former studies from Taiwan, Thailand, and other Southern Asian regions, such as Guangdong Province in China, where the Hb Bart's disease is the main cause for NIHF., ${ }^{71,12}$ This is not surprising since the high prevalence of $\alpha$-thalassemia in Southeast Asian countries. ${ }^{14}$ However, the incidence of Hb Bart's disease-caused NIHF is even higher in our study than that in previous studies in the region. 7,9,10 This is because of the even higher incidence of $\alpha$-thalassemia in our local population in Guangxi Zhuang Region, which is located in Southern China where approximately $8 \%$ population are carriers of $\alpha^{0}$-thalassemia. ${ }^{15}$ A couple with the $\alpha^{0}$-thalassemia trait carrier has a $25 \%$ chance of conceiving a fetus with an $\mathrm{Hb}$ Bart's disease. With a population of 44.9 million and the annual birth of 1 million in the region, there would be more than 850 pregnancies each year affected by Hb Bart's disease. However, since 2000, an effective prenatal screening method for thalassemia has been established at our center, it is now rare to see $\mathrm{Hb}$ Bart-affected fetus going into the third trimester. All cases of NIHF affected by Hb Bart's disease in our study had no prenatal thalassemia screening, and most of these cases were referred from rural areas.

Chromosomal abnormalities are known as one of the common causes of early-onset NIHF. ${ }^{7,13}$ Inconsistent with previous studies, chromosomal abnormalities were the second most common cause of NIHF in our study with the incidence of $13.5 \%$. Chromosomal abnormalities-caused NIHF were usually detected at early gestational age, 52.3\% cases in our study were diagnosed between 15 and 19 
e114 Etiology and Outcome of NIHF in Southern China He et al.

Table 2 GA at presentation of cases of hydrops fetalis according to etiology

\begin{tabular}{|l|l|l|l|l|l|l|l|}
\hline Etiologies & Cases & $\begin{array}{l}<\mathbf{1 4} \mathbf{w k} \\
\text { (cases) }\end{array}$ & $\begin{array}{l}\mathbf{1 5 - 1 9} \mathbf{w k} \\
\text { (cases) }\end{array}$ & $\begin{array}{l}\mathbf{2 0 - 2 4} \mathbf{w k} \\
\text { (cases) }\end{array}$ & $\begin{array}{l}\mathbf{2 5 - 2 9} \mathbf{w k} \\
\text { (cases) }\end{array}$ & $\begin{array}{l}\mathbf{3 0 - 3 5} \mathbf{w k} \\
\text { (cases) }\end{array}$ & $\begin{array}{l}\text { Median } \\
\text { GA (wk) }\end{array}$ \\
\hline Hb Bart's disease & 298 & 4 & 15 & 168 & 97 & 14 & 25 \\
\hline Chromosomal & 65 & 3 & 34 & 19 & 6 & 3 & 18 \\
\hline Cardiac & 31 & 1 & 3 & 2 & 17 & 8 & 26 \\
\hline Infections & 7 & 0 & 0 & 5 & 2 & 0 & 23 \\
\hline TTTS & 4 & 0 & 1 & 2 & 1 & 0 & 22 \\
\hline Meconium peritonitis & 4 & 0 & 0 & 3 & 1 & 0 & 23 \\
\hline Chylous & 3 & 0 & 0 & 2 & 1 & 0 & 23 \\
\hline CCAM & 3 & 0 & 0 & 3 & 0 & 0 & 22 \\
\hline Thanatophoric dysplasia & 2 & 0 & 0 & 1 & 1 & 0 & 24 \\
\hline Twin aortic perfusion & 1 & 0 & 0 & 1 & 0 & 0 & 23 \\
\hline Diaphragmatic hernia & 1 & 0 & 0 & 1 & 0 & 0 & 23 \\
\hline Urethral obstruction & 1 & 0 & 0 & 1 & 0 & 0 & 22 \\
\hline Idiopathic & 63 & 2 & 11 & 24 & 18 & 8 & 25 \\
\hline
\end{tabular}

Abbreviations: CCAM, congenital cystic adenomatoid malformation of the lung; CMV, cytomegalovirus; GA, gestational age; TTTS, twin-to-twin transfusion syndrome.

gestational weeks ( - Table 2 ). The underlying mechanisms of chromosomal abnormality-induced fetal hydrops remain unknown, but obstruction of lymphatic flow has been postulated as the mechanism in Turner's syndrome with cystic hygroma, which is often found in the fetal neck, abdomen, or thoracic regions. Turner's syndrome is the most common chromosomal abnormalities in our study with the incidence of $51 \%$, followed by trisomy 21 (24.6\%), trisomy 18 (13.8\%), and trisomy 13 (7.7\%). The high incidence of chromosome abnormalities seen in NIHF suggested that offering the invasive test to rule out chromosomal abnormality is crucial in working up the etiology of NIHF.

Cardiac abnormities caused of NIHF can be divided into structural malformations, arrhythmias, and cardiomyopathy. Similar to other studies, ${ }^{4,7}$ cardiac anomalies were also a major cause of NIHF in our study, accounting for $6.4 \%$ of all cases of NIHF. Fetal arrhythmia and congenital heart block were two common causes of NIHF in our studies, which often occurred after 24 weeks of gestation. Previous studies also showed that fetal arrhythmia caused hydrops occurred with a median gestational age of 29 to 32 weeks. ${ }^{6,16}$ The reason why the fetus is more prone to arrhythmias at later gestations is not clear but may be related to changes in conduction velocities in the aberrant pathways. ${ }^{17}$ Cardiac structural defects caused NIHF are often associated with chromosomal abnormalities and poor perinatal outcomes. ${ }^{11}$

Intrauterine infection with a wide variety of viral, bacteria, or parasites can induce NIHF. ${ }^{11}$ Parvovirus B19 was reported as the most common cause of NIHF, accounting for almost onefourth of all cases NIHF in Brazil and Tohoku. ${ }^{18,19}$ However, in our study, only two cases of NIHF were caused by parvovirus B19 infection. The remaining five cases of infection-related NIHF in our study were caused by cytomegalovirus, another common viral infection leading to NIHF. The infection-caused
NIHF detected at 20 to 24 weeks' gestation in our study is consistent with the previous study in which the mean presentation of gestational age was 23 weeks. ${ }^{18}$ This might be due to the increase in fetal red cell mass between 20 and 24 weeks which makes the fetus more susceptible to bone marrow suppression by virus infection in addition to the relative immaturity of the fetal immune system at this time. ${ }^{7}$

Studies indicated that with complete prenatal and postnatal evaluations, the etiology of NIHF could be revealed in up to $85 \%$ cases. ${ }^{20}$ However, despite of throughout prenatal as well as postnatal evaluation, the etiology was unknown in $13.1 \%$ of the cases of NIHF in our study, which is consistent with other studies where the idiopathic cases of NIHF varying from 5.2 to $35 \%$. $6,7,9,10,13$

The survival rate in our study was low compared with other studies ${ }^{4,21,22}$ because most couples opted to terminate their pregnancy. Also, Hb Bart's disease and chromosomal abnormalities are the two most common causes of NIHF in our study, which are known to carry a poor prognosis. Therefore, knowing the high prevalence of $\alpha^{0}$-thalassemia carrier in our population, an effective prenatal screening program to provide patients the opportunity for early prenatal diagnosis and counseling may be the most effective way to lower the incidence NIHF in our region.

\section{Conflict of Interest}

All authors declare no conflict of interest. The authors alone are responsible for the content and writing of the article.

\section{Ethical Approval}

Guangxi Zhuang Autonomous Region Women and Children Care Hospital Ethics Committee approved the publication of this article. 


\section{Acknowledgments}

All authors sincerely thank Xiaofeng Wang for advice and for revising this article. We are grateful to our current laboratory members for their helpful comments on the article. The work was supported by Natural Science Foundation of China (grant no: 81660034), Natural Science Foundation of Guangxi (grant nos: 2013GXNSFAA019247, 2016GXNSFAA380078), the Health Department of Guangxi Province (grant nos: Z2014146, Z2011060, S201613, Z2012020, S201309-04), and Guangxi Science and Technology Project (grant nos: Gui 14124004-1-5, Gui 1598012-21].

\section{References}

1 Graves GR, Baskett TF. Nonimmune hydrops fetalis: antenatal diagnosis and management. Am J Obstet Gynecol 1984;148(05): 563-565

2 Okeke TC, Egbugara MN, Ezenyeaku CC, Ikeako LC. Non-immune hydrops fetalis. Niger J Med 2013;22(04):266-273

3 Sohan K, Carroll SG, De La Fuente S, Soothill P, Kyle P. Analysis of outcome in hydrops fetalis in relation to gestational age at diagnosis, cause and treatment. Acta Obstet Gynecol Scand 2001;80(08):726-730

4 Santolaya J, Alley D, Jaffe R, Warsof SL. Antenatal classification of hydrops fetalis. Obstet Gynecol 1992;79(02):256-259

5 Suwanrath-Kengpol C, Kor-anantakul O, Suntharasaj T, Leetanaporn R. Etiology and outcome of non-immune hydrops fetalis in southern Thailand. Gynecol Obstet Invest 2005;59(03):134-137

6 Ismail KM, Martin WL, Ghosh S, Whittle MJ, Kilby MD. Etiology and outcome of hydrops fetalis. J Matern Fetal Med 2001;10(03): 175-181

7 Heinonen S, Ryynänen M, Kirkinen P. Etiology and outcome of second trimester non-immunologic fetal hydrops. Acta Obstet Gynecol Scand 2000;79(01):15-18

8 McCoy MC, Katz VL, Gould N, Kuller JA. Non-immune hydrops after 20 weeks' gestation: review of 10 years' experience with suggestions for management. Obstet Gynecol 1995;85(04): $578-582$
9 Bellini C, Donarini G, Paladini D, et al. Etiology of non-immune hydrops fetalis: An update. Am J Med Genet A 2015;167A(05): 1082-1088

10 Anandakumar C, Biswas A, Wong YC, et al. Management of nonimmune hydrops: 8 years' experience. Ultrasound Obstet Gynecol 1996;8(03):196-200

11 Liao C, Wei J, Li Q, Li J, Li L, Li D. Nonimmune hydrops fetalis diagnosed during the second half of pregnancy in Southern China. Fetal Diagn Ther 2007;22(04):302-305

12 Lallemand AV, Doco-Fenzy M, Gaillard DA. Investigation of nonimmune hydrops fetalis: multidisciplinary studies are necessary for diagnosis-review of 94 cases. Pediatr Dev Pathol 1999;2(05): 432-439

13 Swain S, Cameron AD, McNay MB, Howatson AG. Prenatal diagnosis and management of nonimmune hydrops fetalis. Aust N Z J Obstet Gynaecol 1999;39(03):285-290

14 Weatherall DJ. Keynote address: The challenge of thalassemia for the developing countries. Ann N Y Acad Sci 2005;1054(01):11-17

15 Xiong F, Sun M, Zhang X, et al. Molecular epidemiological survey of haemoglobinopathies in the Guangxi Zhuang Autonomous Region of southern China. Clin Genet 2010;78(02):139-148

16 Iskaros J, Jauniaux E, Rodeck C. Outcome of nonimmune hydrops fetalis diagnosed during the first half of pregnancy. Obstet Gynecol 1997;90(03):321-325

17 Kleinman CS, Copel JA. Electrophysiological principles and fetal antiarrhythmic therapy. Ultrasound Obstet Gynecol 1991;1(04): 286-297

18 Cubel RC, Garcia AG, Pegado CS, et al. Human parvovirus B19 infection and hydrops fetalis in Rio de Janeiro, Brazil. Mem Inst Oswaldo Cruz 1996;91(02):147-151

19 Yaegashi N. Pathogenesis of nonimmune hydrops fetalis caused by intrauterine B19 infection. Tohoku J Exp Med 2000;190(02): $65-82$

$20 \mathrm{Ng} \mathrm{ZM}$, Seet MJ, Erng MN, Buendia F, Chang AS, Sriram B. Nonimmune hydrops fetalis in a children's hospital: a six-year series. Singapore Med J 2013;54(09):487-490

21 Ota S, Sahara J, Mabuchi A, Yamamoto R, Ishii K, Mitsuda N. Perinatal and one-year outcomes of non-immune hydrops fetalis by etiology and age at diagnosis. J Obstet Gynaecol Res 2016; 42(04):385-391

22 Thong XY, Lee LY, Chia DA, Wong YC, Biswas A. Management and Outcomes of Fetal Hydrops in a Tertiary Care Centre in Singapore. Ann Acad Med Singapore 2017;46(01):4-10 